\title{
Syntelencephaly: postnatal sonographic detection of a subtle case
}

\author{
Arnold C. Merrow • Ritu Shah
}

Received: 7 April 2010 /Revised: 29 April 2010 / Accepted: 14 May 2010 /Published online: 4 June 2010

(C) Springer-Verlag 2010

A newborn with D-transposition of the great vessels was evaluated by cranial US. Abnormal gray and white matter cross the midline at the expected location of the body of the corpus callosum (Fig. 1, arrow). Only an intact genu and splenium of the corpus callosum were identified, and the septum pellucidum was absent. Syntelencephaly was suggested. The subsequent MRI confirms an abnormal gray matter connection of the cerebral hemispheres (arrows) (Fig. 2, black arrowhead=genu, white arrowhead= splenium) and also shows an azygous artery and partially absent falx. Other common findings of syntelencephaly (also

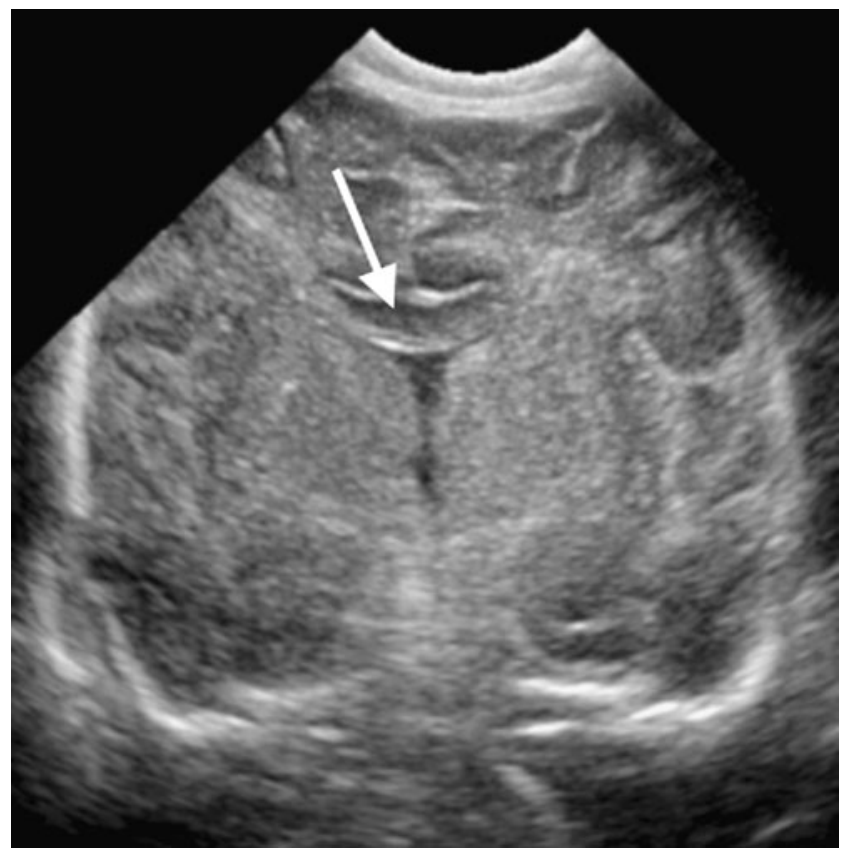

Fig. 1 Coronal US image

\section{A. C. Merrow $(\bowtie)$}

Department of Pediatric Radiology, Children's Hospital of Alabama, 1600 7th Ave. South, Suite 306, Birmingham, AL 35233, USA e-mail: acmerrow05@yahoo.com

\section{R. Shah}

Department of Radiology, University of Alabama at Birmingham, Birmingham, AL, USA

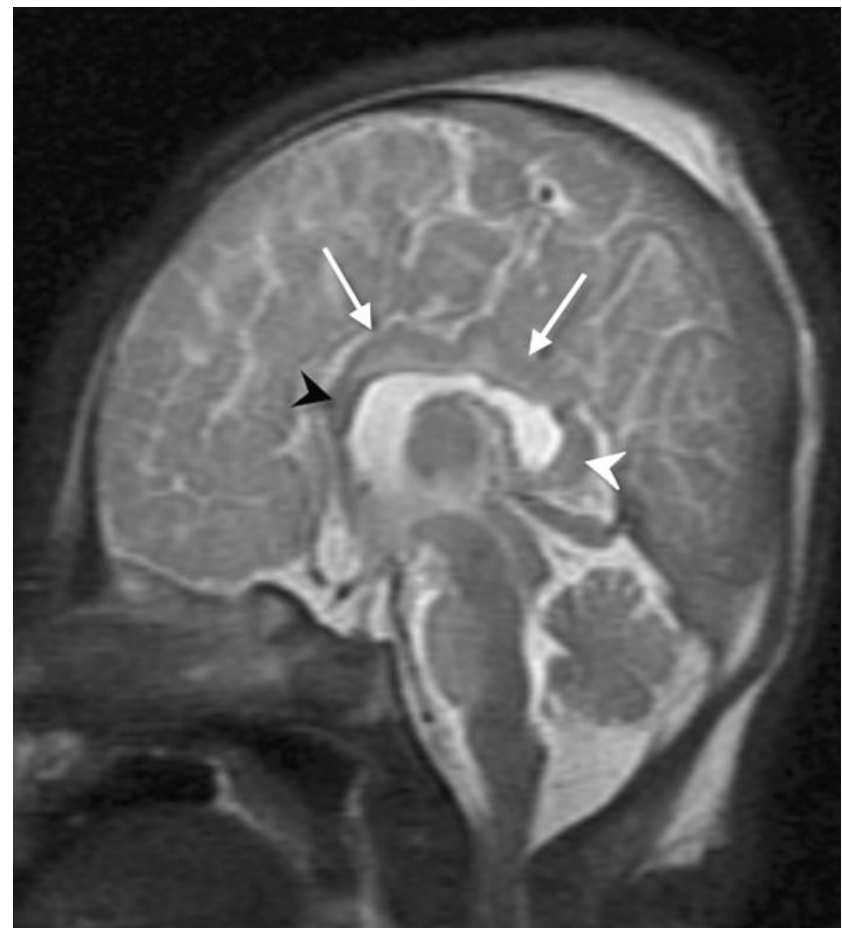

Fig. 2 Sagittal T2-W SSFSE MRI

referred to as the middle interhemispheric variant of holoprosencephaly), such as sylvian fissure continuity across the vertex midline and dorsal cyst were not seen [1].

The key imaging feature in all forms of holoprosencephaly is a degree of failed separation of the cerebral hemispheres. The noncleavage of syntelencephaly affects the posterior frontal and parietal lobes versus the more anterior frontal lobes and deep gray nuclei in lobar holoprosencephaly [2].

\section{References}

1. Simon EM, Henver RF, Pinter JD et al (2002) The middle interhemispheric variant of holoprosencephaly. AJNR 23:151-156

2. Pulitzer SB, Simon EM, Crombleholme TM et al (2004) Prenatal MR findings of the middle interhemispheric variant of holoprosencephaly. AJNR 25:1034-1036 